\title{
Ian McHugh
}

\section{University of Canberra}

\section{The narrative of assemblage (and the assemblage of narrative)}

\begin{abstract}
:
This paper argues that narrative theory and the political theory of assemblage complement each other in ways that can both illuminate and contribute to political struggle. Assemblage thinking points to complex, catalytic interactions that might open further lines of inquiry to key aspects of narrative analysis, such as meta-narrative, heteroglossia and collectivisation of memory. In turn, narrative theory offers the prospect of further elaborating the key processes by which human social assemblages are composed and decomposed and thus filling some of the critical 'silences and absences' (Anderson et al. 2012: 212) of assemblage theory.
\end{abstract}

\section{Biographical note}

Ian McHugh is an award-winning short fiction writer. His stories have appeared in magazines and anthologies in Australia and internationally, including The Year's Best Science Fiction, The Year's Best Australian Fantasy and Horror, and Award Winning Australian Writing. His debut short story collection, Angel Dust, was shortlisted for the Aurealis Award for Best Collection in 2015. Ian is a current doctoral candidate at the University of Canberra.

\section{Keywords:}

creative writing - assemblage - narrative

My interest in this paper is the convergence of narrative theory with the political theory of assemblage. But, while it's all very well to talk about convergences of theory, the phenomenon of theorists from different disciplines talking about complementary topics in complementary ways is hardly remarkable. To be more than an idle intellectual exercise, a convergence needs to tell us something more than what we more or less already knew. To repurpose a line, to be of value, a convergence of theory should 'allow us to do certain things and enable us to think in certain ways that were not possible before' (Allen 2011: 154). For the creative writer, researcher, or narrative theorist, assemblage, as with any new perspective, should be a 'proverbial grain of sand that... usefully irritate[s] taken-for-granted assumptions' (McCann 2011: 143). 
So, how can assemblage usefully irritate us? If a writer adopts a radical stance, and considers that 'the goal of research is not the interpretation of the world but the organization of its transformation' (Russell et al. 2011: 580), then narratives, including fictional and creative works of writing, are a powerful tool for struggle. Jerome Bruner (1991) suggests that social domains are organised through narrative; assemblage provides a way to articulate that connection explicitly and politically.

Assemblage is not a new concept in political philosophy. However, while it has been taken up by scholars across a variety of social sciences and humanities disciplines, assemblage thinking has not gained the kind of traction that narrative thinking has. The concept had its first full articulation in 1980 in French, in Gilles Deleuze and Felix Guattari's doorstopper, $A$ Thousand Plateaus, first published in English in 1987. Readers familiar with Bourdieu's fields, Foucault's or Althusser's variations on apparatus, Latour's networks, or the concerns of all of the above with power, will find a good deal of familiarity in what follows. Like fields and apparatuses and networks, assemblages are a way of conceptualising formations of human social relations and power (that is, as assemblages). Assemblage, though, builds from all of these other concepts in interesting ways.

In assemblage theory, 'assemblage' serves as an English translation of Deleuze and Guattari's original French term agencement, rather than its direct French cognate, assemblage (Nail 2017). Where assemblage in common English usage is either noun or verb - either an assemblage or a process of assembling - agencement is simultaneously both (DeLanda 2016). That is, the Deleuze-Guattarian assemblage simultaneously denotes both an existing social formation and the continual process of assembling and re-assembling that formation; the product is inseparable from its constant (re)production. It follows from this that assemblages are historical entities, that exist and change over time. A social assemblage is like the proverbial sailing ship that is replaced one piece at a time until no original components remain. And the new components might all be quite noticeably different from those they replace: different kinds of timber, different style of rigging, updated armaments, different internal fit out, another country's flag, a new name, and so on. At any given point in this process of change, the whole remains the same ship, even though in the aggregation and interaction of its components it's quite a different ship. The thing and the process of continually (re)becoming the thing are one and the same - there is no final product separate from the ongoing historical processes of its production (Nail 2017). Australia today is the same historical entity that was formed on 1 January 1 1901, despite being, in many respects, vastly different from the White Australian bastion of empire it originated as. While much of the political and normative cultural infrastructure remains recognisably similar, increasingly much of this infrastructure seems - to borrow Fintan O'Toole's observation of his native Ireland - like the monocultural hangover of an increasingly pluralist society (quoted in Schultz 2017). In the same way, Australia today is both the same as and different from the entity it will be when current contests over climate change, Australia Day, coal mining, Indigenous recognition, gender violence, treatment of refugees, water allocation, foreign influence and so on have played out. 'Contest' is the critical point here: cultural infrastructure does not shift easily, and change will always be contested.

Literary formulas are expressive mechanisms for the preferred (dominant) values of a culture. When a culture's values or attitudes change, accepted literary formulas change to reflect, exploit and articulate this (Cawelti 1976). The narratives that emerge from within a social assemblage, both fiction and non-fiction, can help to illuminate changes that may be obscured by structural continuity and the tensions that emerge in processes of change. For example, in the pre-federation Australian colonies, lost child stories, which fiction and reportage intensely cross-fertilised, were prominent, and functioned as morality tales about the indifference of 
the land to human settlement. These stories reflected the apprehension and sense of alienation felt by the colonists, settling in a new and unfamiliar place that might never seem entirely 'home' (Pierce 1999). Following federation, new stories that fitted the lost child myth virtually disappeared, as concern turned to nation-building and narratives of progress, the dominant culture (at least superficially) confident and unchallenged in its imperialism, chauvinism and overt racism.

This period ended with Britain's abrupt imperial retreat from Asia. From the 1950s onwards, the lost child myth is revived, but the agents of threat are now human rather than environmental, through institutional failure, malevolence or indifference. Peter Pierce attributes the difference in the nineteenth and twentieth century stories to a preoccupation in the latter period with 'the rending of communities' (1999: 96), as opposed to anxiety over their establishment in unfamiliar surrounds prior to federation. The political context of the most recent period for Australia encompasses the rise of feminism and Aboriginal political activism; the ending of the White Australia; the end of the British Empire as Australia's security guarantor; materialism and class politics; the new alienation of suburbanism; humaninduced climate change; the American alliance, Cold War and Domino Theory, the War on Terror and, now, America's exit as Asian hegemon. All these are sources of threat for the dominant conservative culture (see Turner 1994; Hartcher 2007; White 2017). The dominant political and cultural infrastructure - the planks and rigging of the sailing ship Australia have remained largely similar, but the aggregation and interaction of forces and components within that structure is vastly different (Schultz 2017), and it is the tensions inherent in this diachronic lag that emerge in the revived and revised formula of the lost child story.

Being historical means being 'historically individuated' (DeLanda 2016: 13, original emphasis) and, from an assemblage perspective, social formations are as much 'concrete individuations', in Deleuze and Guattari's terminology, as human individuals are (1988: 261). One of the defining commitments of assemblage theory, then, is to heterogeneity, both in terms of the components that the assemblage contains and the combination of processes that bring them together. Any given assemblage is composed of a historically distinct combination of agents, objects and relationships that 'jostle, co-exist, interfere and entangle' with each other, easily and uneasily, constructively and disruptively (Allen 2011: 154).

A nation-state, for example, is comprised of components as diverse as a history, a geography, people and communities, regions, cities, transport and utilities infrastructures, an economy and industries, laws, politics, languages, crime, music, art and sporting subcultures, climate zones, ecosystems, resources, vermin, and so on. Each of these components operates through a different set of social or physical processes and logics, and all of these diverse components and their associated processes tangle together to make the nation-state what it is, jostling and interfering with each other, surprising, frustrating and gratifying the human agents who make their living there or who try to transform the national assemblage into something different. Thus, the commitment to historical individuation and heterogeneity is a commitment to complexity as well.

This complex, individuated tangle of forces explains why ideas that work in one context often fail to translate to an apparently comparable situation - or translate differently. Why, for example, one mass-shooting can lead to a wide-reaching firearms ban in Australia, while nearly one mass-shooting a day over a period of five years (Morris 2018) can have no such effect in the United States. One thread that can be followed back from these starkly different outcomes is to the fundamental difference in the naturalised alibi at the root of each culture. While the richness and promise of the American landscape is an alibi for the lionisation of the individual and the ethos of individual achievement, with its attendant suspicion of 
collectivism, the Australian landscape provides the opposite - a foundational conservative socialism and suspicion of individualism (Turner 1993). Clues to these differences are, again, present in the fictional narratives that emerge from each assemblage - the hyper-realist individualism of American noir and fiction of the American West (Cawelti 1976; Napper 2018), for example, versus the social-realist diminution of the individual that tends to occur in the Australian versions of those genres (Napper 2018).

To hold a single thread as the explanation, though, would be mistaken. In Mikhail Bakhtin's notion of heteroglossia, texts reveal both the voice of the individual narrator and the voice that emerges in the relations of the social collective within which they operate (Wertsch 2008). Approaching this with an assemblage mindset points us towards just how complex and multiple those collective voices might be, that they may include the voices of symbolic objects as well as multiple formations of human agents, and that the flows of power and influence will be multidirectional, unpredictable and catalytic. Between Australia and America there are immense differences between political culture and institutions, industry, militarism, patriotism, between dry legalism versus armed insurrection as a national origin story, and between censoring versus mythologisation of frontier violence. There are divergent ideologies around individualism. Guns themselves have vastly different symbolic meanings. In an American context, guns have powerful, complex and contradictory ties to patriotism, race, masculinity, liberal individualism and a positive exceptionalist foundation myth, meanings that are mostly absent from the almost exclusively recreational culture of Australian gun enthusiasts (Kohn 2004). It follows that in a traditional American Western or noir narrative, the use of guns is expected and legitimated, whereas an equivalent Australian story, the use of guns is shocking and denotes failure of social norms. In American narrative, the settings for Western and noir fiction are opposite - the liberating frontier where civilisation conquers savagery on the one hand, and the alienating city where civilisation is corrupted on the other - reflecting the national myth (Cawelti 1976). In an Australian context, the setting for both Western and noir tends to be the same the hostile natural landscape - the two genres collapse into each other (Napper 2018) and the liberation of the former genre is covalent with the alienation of the latter, reflecting a very different national mythology of place and uncertain belonging (see Turner 1993).

Another defining commitment of assemblage theory is to contingency, or what Deleuze and Guattari called 'relations of exteriority' (Dewsbury 2011: 150). Most relations in an assemblage aren't intrinsic to the agents and objects being related. For the most part, they're not filial or genetic relations - like biological descent, for instance - that can't be detached from the agents and objects in question (DeLanda 2016). More often, relations within an assemblage are extrinsic to the agents and objects being related and, therefore, contingent, rather than necessary. This means that the relations between components can change without the components themselves being changed (Dewsbury 2011). It also means that the components of an assemblage identify with the assemblage, but aren't defined by it. So agents and objects can be (and are) mobile within an assemblage and between assemblages (DeLanda 2016) and can (and generally do) belong to multiple assemblages (Allen 2011). A 19-year-old man born in Brisbane can reasonably be said to belong to the assemblages of Australia and Queensland. If the white shoe brigade get their dream and Queensland secedes from Australia tomorrow, this man's relations are changed. In formal terms, he won't be Australian any more, he'll still be a Queenslander but being a Queenslander will have a different quality. He may or may not still feel that he is (or should be) Australian, depending how he prioritised his attachments to the two assemblages. If the man is Aboriginal and Murri, will he now be an Aboriginal Queenslander or will he see himself as part of a national assemblage divided by someone else's nation-state border? Whatever the answers, the 
intrinsic qualities that make him him won't be changed. He'll still be essentially the same 19year-old man born in Brisbane, one day older.

None of the elements touched on in the preceding discussion of Western and noir fiction are static in either American or Australian society, nor in the deployment of the literary formulas they produce. The genres change in complex ways to reflect complex changes in the surrounding social assemblages. As the legitimacy of guns is increasingly challenged within American society, noirish superhero stories, like the recent Marvel-Netflix television adaptations of Daredevil (2015-) and Luke Cage (2016-), gain traction beyond their original limited context, explicitly rejecting the legitimacy of gun violence while still lionising the fantasy of the righteous, rebellious and violent vigilante individual. Even the gun-centric The Punisher (2017-) arguably 'makes vigilantism and guns look scary, severely disturbing, and decidedly unglamorous' (Hughes 2017). In the Australian context of a re-energised Invasion Day counter-narrative, Paul Collis repurposes and suberts the formula of the noir revenge story to illuminate the condition of criminalised Aboriginal masculinity in the 'koori noir' novel Dancing Home (2017). Rebellious vigilantism is revealed as an absurd fantasy, and violence is ultimately self-destructive - the formula scene where the hero 'shows what he can do', demonstrating his superior mastery of violence against a thuggish opponent unrelated to the central plot, in Dancing Home, is the moment where the noir individualist fantasy is derailed and social-realist consequences are imposed.

The flip side of contingency and exteriority is that an assemblage is also not reducible to the aggregate of its components (DeLanda 2016). In addition to their components, assemblages have emergent properties that arise in the relations between the components. Consider an Australian Rules football match. Its components include players, teams, a ball, uniforms, referees, rules, a pitch, a stadium, spectators. Where in all of these components are drama, tension, spectacle, atmosphere, passion, meaning? How does the manufactured and artificial competition of salaried entertainers - or playing amateurs - become so invested with apparent importance that, say, a Collingwood supporter, circa 1989, (or Geelong supporter, a decade later) might become so traumatised that they are unable to watch their team play a finals match live? The qualities that complete the assemblage that is a football match and provide its expressive and symbolic properties - its meaning - exist in between its components and emerge from their interaction in the context of the assemblages constructed around them (for example, leagues, competitions).

Those contexts and the complex hedonic (enjoyment, vicarious achievement), dispositional (need for belonging) and social situational (family, class, community) motives of the participating human agents (Funk \& James 2006) are structured narratively in terms like struggle, communal identities and rivalries, underdog fantasies, dynasties of success, and war. In an Australian context, the dominant football codes of rugby league and AFL are both associated with the Anzac myth, with Australia playing New Zealand in rugby league and, less obviously, Collingwood playing Essendon in the AFL on Anzac Day. This association promotes a particular narrative of masculinity that encompasses both fields of endeavour and, on the one hand, sanitises war as an honourable, rules-based contest and lends the gravitas of an important masculine endeavour to a field of entertainment and play. Thus, a nominally frivolous activity becomes an important facet in the construction of the normative cultural infrastructure and thus, too, carries significant cultural weight in regard to other issues, like race relations, sexuality and male violence towards women.

Change in an assemblage is always immanent, and can be either incremental or radical. Assemblages are autopoietic (Dewsbury 2011), meaning that they have the internal capacity to perpetuate and renew themselves. They're also inherently unstable and ephemeral. 
Australia's pre-colonial history is conventionally narrated as a single civilisational metaassemblage, comprised of a synchronically unbroken continuum of related cultural, national and linguistic assemblages (on the mainland, at least) and a diachronic depth of time that defies the historical imagination of European civilisation. Sixty-five thousand years (Clarkson et al. 2017) of continuous storytelling embeds Aboriginal people in the land (Stilz 1991). Colonisation upended traditional ways of life, displaced and dispossessed the people, devastated much of their cultural knowledge and invented new, unitary categories of 'Aboriginal' and 'Indigenous' that are variously used and resisted by the individuals and peoples they encompass. Does this cataclysm mark a fundamental break between the 2,500 generations of the preceding civilisation and the Aboriginal cultures and societies that exist today? Whether you see it as one assemblage or several depends on how you interpret it, and an assemblage perspective doesn't demand that the answer be clearly one or the other. Often the boundaries of an assemblage aren't entirely clear and are, therefore, open to dispute (Marcus \& Saka 2006).

The difficulty of this question is illuminated in Bill Neidjie's Story About Feeling (1989). Having left his traditional country at 15 years of age, Neidjie returned 50 years later to try and help preserve his people's traditional knowledge. He is acutely conscious of what his people have lost, and what was likely lost from his own knowledge in that half-century gap, that his project of reconstruction is based at least as much on a feeling of rightness as on the complete and entire reproduction of knowledge that would have been handed on from his male ancestors. 'All my uncle gone' he says, 'but this story I got im. They told me, taught me and I can feeling' (168). Neidjie is conscious, too, that his people's society, and Aboriginal society more broadly, doesn't and can't exist in isolation from the non-Aboriginal society with which it has been forced to share its social space - and, thus, Story About Feeling is addressed to a non-Aboriginal audience. These anxieties of dispossession, of loss of knowledge and culture and of overlapping and unequal social geographies, are prominent in recent works of fiction by Aboriginal writers, including Paul Collis's Dancing Home, Claire Coleman's Terra Nullius (2017), and Alexis Wright's The Swan Book (2013). From an assemblage perspective, these anxieties don't have to be neatly resolved one way the other the dialectic can remain open. Change in an assemblage may be incremental or dramatic and threads of continuity can traverse even points of extreme disjuncture. It is the human agents who decide what those continuities and discontinuities mean and whether an assemblage remains the same, is something new, or a more open and unresolved position in between.

Constructionist approaches to narrative analysis are centrally concerned with the influence of collectively held meta- or macro-narratives on construction of individual stories. These are the available historical and cultural repertoire of narrative resources that inform individual story construction. While constituting their personal narratives, individual storytellers draw on these public or meta-narratives (or schematic templates or cultural scripts, and so on) and, thus, the meta-narratives facilitate dialogue between storyteller and audience (Esin et al., 2013). Despite the centrality of these meta/macro-narratives/templates/scripts to constructionist analysis, Matti Hyvarinen admits that 'very little is known about how exactly [these] impose their models on individual action or narration' (2012: 455). Perhaps assemblage theory points to the complex, catalytic interactions of downward causality that can further open this line of inquiry. A 2014 analysis of reading group responses to Kate Grenville's The Secret River suggests exactly this complex array of influences behind the diverse responses to the novel (Nolan \& Clarke 2014), which ranged across racist excuses, equivalence narratives, 'cross cultural empathy and self-conscious critique of white racism', and epistemological questions around 'the implications of the past for the present' (33). Significantly, these socially negotiated readings, contrasted by the researchers to 
'professional' readings of Grenville's novel, 'remain provisional, open-ended and available for revision on the basis of conversation' (33).

The forces of both autopoiesis and entropy may include physical processes that lack intentionality, but the intentional forces of preservation and change in an assemblage occur through the struggle for power and position amongst individual agents (Collier 2006). So agential change is always a contest, and historical is meant in the Marxist (or Bourdieusian or Foucauldian) sense, where the relations and exercise of power are the critical aspect of processes of social formation and reformation. Such change might be intentional, in the sense of having human agency behind it, but assemblages also exercise downward causality on their participants, in the form of both limiting rules and norms, and the opportunities that arise in the potential for solidarity, collective mobilisation and established strategies for successful struggle (DeLanda 2016). Because of the complexity of the processes and relations in play, change in assemblages tends not to feature simple or predictable linear causality (McFarlane \& Anderson 2011). Change under these circumstances tends to occur through the mechanism of catalysis (Harman 2008), where a cause is merely a catalyst that doesn't automatically result in a defined or predictable effect.

The Fraser Government's decision to actively promote the year 1988 as Australia's Bicentenary provided an obvious focal point for Aboriginal activism (McKenna 2010), but why, having persisted at a relatively lower key since, did Invasion Day protests return to such sudden prominence three decades later? Why was the revitalisation sparked by a pair of urban city councils? Answers are available to us after the fact, but these specific outcomes weren't predictable beforehand, as they would be if cause and effect were straightforwardly linear.

James Wertsch begins to recognise the multidirectional, unpredictable and catalytic flows of power and influence within assemblages when he proposes a 'distributed version' of collective memory, in which memory is held both 'socially in small group interaction' and 'instrumentally' in 'external symbolic storage', especially texts (2008: 121) - and including fictional texts. These instruments of 'external symbolic storage' organise memory in moreor-less intentional ways, most especially in the form of narratives, that impose a shape on the past to suit the needs of the present (122).

But assemblage theory tells us that the needs of the present are ephemeral, and never fixed in place for long. When they move, or are contested, then the outcome of that movement for change or that contest will be non-linear and unpredictable, as with the outcome of the current struggle in Australia, over 26 January as the date of Australia Day, and the narrative it represents by marking the arrival of the First Fleet of British convicts. Recent promotion of the counter-narrative has included a trio of city councils deciding to stop conducting citizenship ceremonies on Australia Day, the national Triple J radio station moving the date of their annual Hottest 100 music countdown, and more people reportedly turning out for the Invasion Day protest in Melbourne in 2018 than for the Australia Day march that preceded it (Knaus \& Wahlquist 2018). This re-energised activism has also produced a significant backlash in support of the hegemonic narrative, including the Australian federal government revoking those city councils' rights to conduct citizenship ceremonies (Heffernan 2017). The competing narratives represent a struggle for power and position in the fields of Australian politics and society. What further event might catalyse a change in the hegemonic narrative of Australia Day, what direction that change might take, whether there will even be a catalyst that triggers significant change, or whether, conversely, that tipping point hasn't already been passed, are as yet unknown and will only be known in retrospect. 
Assemblage theory conceptualises the forces of autopoiesis and entropy in terms of what Deleuze and Guattari called territorialisation and coding. Territorialisation refers to the mechanisms that enforce the boundaries and internal coherence of the assemblage (DeLanda 2016), the rules, laws, conventions of behaviour, the exercise of sanctioned violence and authority, physical barriers and limits - the enforcement of Australia's policy of denying entry to refugees arriving by boat, for example. Coding refers to the discursive, expressive, symbolic elements that legitimate and make sense of the assemblage and its enforcement the threatening discourses of terrorist infiltration and Islamophobia, bundled with the discourse of national sovereignty, that justify turning back the boats.

Territorialisation and coding each have their opposites. De-territorialising forces are those that breach the boundaries or disrupt the coherence of an assemblage, such as the activism of a social movement like the Refugee Action Committee disrupting from within, or the criticisms of the UN Human Rights Commission intruding from without. Decoding mechanisms are the discourses and expressions and symbols that challenge the legitimacy of the assemblage in its present form - the discourse of universal human rights deployed by refugee advocates to challenge the discourses of national security and sovereignty. Territorialising and de-territorialising, coding and decoding mechanisms are rarely in balance, but are all always in play at once. This means that social formations that are conventionally portrayed as monolithic are in reality ephemeral and only ever partly internally consistent and coherent (McCann 2011) - no product separable from its ceaseless production.

Despite all of this, a peculiarity of assemblage theory, unlike other radical theories, is that when it comes to identifying the particular ways in which specific assemblages are composed and decomposed, it tends to produce only 'silences and absences' (Anderson et al. 2012: 212). This is perhaps because of the philosophical commitment to heterogeneity, or perhaps because it is positioned as a 'phenomenon that forces or enables thought (and not a set of routines or protocols to be mastered and repeated)' (213). However, Jerome Bruner (1991) suggests that the domains of human self-knowledge, of self, society and culture, are organized primarily through the practice and principles of narrative. This raises an intriguing possibility: if the social processes of assemblage occur through the struggles of human agents, does it follow that the forces of composition and decomposition that those human agents generate are discursively organized primarily through the practice and principles of narrative?

If that is the case, then the discursive mechanisms of assembling and re-assembling - that is, coding and decoding - would be primarily narratives. Well, the contestation of any social change is a struggle of narratives as much as of power, and the two are inextricably intertwined. It's through narratives that we attach and detach ourselves to and from particular assemblages, and validate our struggles to improve or defend our positions within them. It's through narratives that the contingent, extrinsic relations that embed us in assemblages are legitimated and given meaning. It's through narratives that the boundaries of assemblages are asserted and disputed. It's through narratives that assemblages have the meanings that they do or even have meaning at all.

Neither writing or creative storytelling, nor the combination of the two, are automatic or neutral outcomes of narrativity. Writing is a generative practice, revealing subjective truths in the selective constructions of the author (Banks 2012). Fiction, similarly - and creative storytelling more broadly - 'is the selective ordering of experience' in a narrative 'fashioned out of real and imagined happenings' that, again, constructs certain truths (Banks 2012: 160). Performed as public acts, the purpose of writing and creative storytelling, separately or 
combined, is to generate social and cultural capital (Bourdieu 1993). In one way or another, they are strategies of struggle, to advance or defend the positions of the individual authors, the coalition of agents with whom they align themselves within a given assemblage, or the assemblage as a whole. For example, novels by Australian Aboriginal writers that address the issues and experiential truths of Aboriginal people, like The Swan Book, Terra Nullius and Dancing Home, use fiction to interrogate the position of Aboriginal people in Australia, as a means of advancing that position and, at the same time, promoting the position of the authors both politically and professionally. By the same token, these novels have all emerged in the context of increasingly frayed censorship of Aboriginal voices, lives and histories that, while still bitterly contested, has opened opportunities for the advancement of positions that didn't previously exist. Fictional narratives aren't limited to merely reflecting changes and contests in social assemblages, they participate in and contribute to them. The novels noted above have all contributed to the further opening of space for advancement of Aboriginal positions, as did earlier novels by Aboriginal writers, like Kim Scott's Benang (2000) and Wright's own Carpentaria (2006), as well as novels by non-Aboriginal writers that critically engage with discourses of race and colonial mythology, like The Secret River and Andrew McGahan's The White Earth (2004).

The contributions of fictional narratives to coding and de-coding are complex and multifaceted - as with Daredevil and Luke Cage contributing to de-coding of hegemonic American gun discourse, while still actively coding the related myth of vigilante individualism. The Swan Book, as well examining the fantasy of black co-optation of white power, addresses Australia's national refugee policy, turning white Europeans into climate refugees and having them turned away, unwanted, from every place they seek sanctuary. Wright uses this reversal to skewer exophobic Australian attitudes and contrast them to the historical stories of empathy demonstrated by Aboriginal people towards the European invaders. When a white refugee woman arrives in what is, effectively, an Aboriginal concentration camp in Wright's future northern Australia, 'to prove that [the camp's inhabitants are] not assimilated into the Australian way of life, the ancient laws of good manners about welcoming strangers [are] bestowed' (32).

Turning to the practice of creative writing as research, Stephen Frosh calls for 'disintegrating qualitative research' (Brinkmann 2012: 7, emphasis added). Narratives fragment as well as integrate, both for human subjects and the assemblages they participate in. A person's reflective efforts at life story will seek to cohere and rationalize their life choices and experiences (Bamberg 2006); the small, day-to-day, interactional stories the same person tells, by contrast, will tend to 'entertain different, often contradictory, positions' simultaneously, and perhaps even 'strategically avoid fixity' (75). As in assemblage theory's open dialectic of coding/decoding, territorializing/de-territorializing, Frosh wants researchers to 'hold onto the dialectic of deconstructionist fragmentation and narrative integration' (75). A history of the Australian nation-state, like Manning Clark's six-volume epic, seeks to offer a coherent explanatory narrative of what 'Australia' is and means and how it came to be; at the same time, and even without a major challenge to the overarching hegemony, that history is contested and contradicted day-to-day by personal, interactional and smaller scale narratives that don't cohere to the hegemonic explanation.

Svend Brinkmann (2012) suggests that literary novels offer a more suitable vehicle for holding onto this open dialectic than conventional research reporting. Restricting this claim, as Brinkmann does, to the 'literary novel' seems unnecessary when any work of creative storytelling, whatever its form or genre, exists on a continuum of mimesis to formula (Cawelti 1976) and therefore offers some version of Frosh's open dialectic, however asymmetrical. Creative writers, while also finding coherent narratives, have 'much more 
leeway in staying with the incoherent and disordered' characteristics of lived experience (Brinkman 2012: 7) and of human social assemblages, and to 'write into and out of problems of representation' without the constraints of conventional academic discourse (Banks 2012: 161). The contradictory, personal and interactive are captured in fiction, exposing the everyday discontinuities and variable instantiations of dominant discourses. Novels like Breath by Tim Winton (2008) and Down The Hume by Peter Polites (2017) in different ways each expose the shortcomings of the dominant discourse of Australian masculinity: Winton by exploring the perverse consequences of the combination of 'liberality' with an absence of rites of passage and 'codes of belonging' (quoted in Rubbo 2008), Polites by exposing the linkages between traditional Australian masculinity and domestic violence, broadening the 'seldom challenged' conventional discourse to encompass relationships between men and detaching hypermasculinity from heterosexuality (quoted in Elliott 2017). In both cases, creative storytelling is a vehicle to explore complexities and contradictions, to decode and open up the discursive space, without also needing to re-code and close it off again.

Historians are often concerned by the potential for historical fictions to 'confuse ... understanding of real historical events' (Nolan \& Clarke 2014: 21; also see Mitchell 2010). Yet, from a Herodotean stance, history, concerned with 'exploring truth through the narration of many stories, fables, and parables, and engaging with histories that are social, cultural, religious, gendered, sexual, and erotic, as well as diplomatic, political, and military' (Curthoys \& Docker 2013: 203), lends itself to creative, imaginative and immersive accounts - including fictional ones. While all the readers in Maggie Nolan and Robert Clarke's study of reading group responses to The Secret River were very clear to delineate the fictional work from a non-fiction history, the researchers concluded that their evidence suggests lay readers 'are not convinced by the argument that there is a need to distinguish categorically between history and fiction; they seem comfortable reading in the space between these modes of writing without necessarily seeing them as the same' (2014: 25). Lay readers may thus be comfortable with the possibility that a work of fiction can offer historical truths without itself being a literally true account. A common theme among the readers was to emphasise the immediacy and intimacy of engaging with the historical period through the medium of the fictional novel and, for most of the readers in the study, the effect of the novel was to throw the history at them with 'full force' (24). Thus, the readers' internalisation of this history and its ramifications was affected by the novel and its socialisation among their peers, with affect being a catalytic pre-condition for political action (22).

The characters in a novel might be recognizable as belonging to a particular ethnicity or economic class or social category, and with characteristics that flow from that, but still be read and understood as flawed and individual human agents. The speed-addicted Aboriginal men who steal a car and set off from Sydney to Dubbo on a quest for revenge in Dancing Home (Collis, 2017), for example, are recognizable avatars of criminalised Aboriginal manhood, moulded by racism, white institutional violence and black communal violence. But, while these interconnected influences are vividly drawn, the characters remain autonomous agents, making choices, possessing both individual virtues and flaws, and shaping their own destinies within the constraints imposed by the social assemblage around them. That is, the fictional characters present the qualities of individual human beings, rather than being subsumed by their representativeness as real human beings might be in a conventional research report. The complex interaction of individual characteristics and agency with the downward causality of the assemblages within which human individuals operate can be captured in a work of fiction in a way that can be much harder to achieve in conventional research writing. Placed in the context of ongoing contests around the overrepresentation of Aboriginal people - men and boys especially - in the penal system, Collis 
offers a re-coding of discourses around this population from 'criminalised' to 'disenfranchised', and one that is affective because, to borrow the responses of The Secret River readers (Nolan \& Clarke 2014), it is immediate, intimate and humanised.

Every time we write stories for others to consume we are coding or decoding - very likely in multiple ways and both at once, since narratives require both 'canonicity and breach' (Bruner 1991: 11). Every narrative we present is a catalyst, even if it's only in the tiniest way. To paraphrase Brian Massumi: a narrative is a brick. It can be used to build the courthouse of reason. Or it can be thrown through the window (quoted in Russell et al. 2011: 278).

\section{Works Cited}

Allen, J 2011 'Powerful Assemblages?', Area 43, 2: 154-157

Anderson, B, M Kernes, C McFarlane, \& D Swanton 2012 'Materialism and the Politics of Assemblage', Dialogues in Human Geography 2, 2: 212-215

Bamberg, M 2006 'Biographic Research, Quo Vadis? A Critical Review of "Big Stories” from the Perspective of 'Small Stories', in K Milnes, C Horrocks, N Kelly, B Roberts, \& D Robinson (eds) Narrative, Memory and Knowledge: Representations, Aesthetics, Contexts, University of Hudderfield Press, Huddersfield: 63-79

Banks, S 2012 'Writing as Theory: In Defense of Fiction', in J Knowles \& A Cole (eds) Handbook of the Arts in Qualitative Research: Perspectives, Methodologies, Examples, and Issues, SAGE, Thousand Oaks: 155-165

Bourdieu, P 1993 The Field of Cultural Production, Columbia University Press, New York

Brinkmann, S 2014 'Books of Fiction', in Qualitative Inquiry in Everyday Life: Working with Everyday Life Materials, SAGE, London: 149-177

Bruner, J 1991 'The Narrative Construction of Reality', Critical Inquiry 18, 1: 1-21

Cawelti, J 1976 Adventure, Mystery and Romance: Formula Stories as Art and Popular Culture, Chicago University Press: Chicago

Clarkson, C, Z Jacobs, B Marwick, R Fullagar, L Wallis, M Smith, R Roberts, E Hayes, K Lowe, X Carah, S Florin, J McNeil, D Cox, L Arnold, Q Hua, J Huntley, H Brand, T Manne, A Fairbairn, J Shulmeister, L Lyle, M Salinas, M Page, K Connell, G Park, K Norman, T Murphy \& C Pardoe 2017 'Human occupation of northern Australia by 65,000 years ago', Nature 547: $306-310$

Coker, C (showrunner) 2016- Luke Cage (TV series), Marvel-Netflix, New York

Coleman, C 2017 Terra Nullius, Hachette Australia, Sydney

Collier, S 2006 'Global Assemblages', Theory, Culture \& Society 23, 2-3: 399-400

Collis, P 2017 Dancing Home, University of Queensland Press, St Lucia

Curthoys, A \& J Docker 2013 'The Boundaries of History and Fiction' in N Partner \& S Foot (eds) The SAGE Handbook of Historical Theory, SAGE, Sydney: 202-220

DeKnight, S, D Petrie \& M Ramirez (showrunners) 2015- Daredevil (TV Series), Marvel-Netflix, New York

DeLanda, M 2016 Assemblage Theory, Edinburgh University Press Ltd, Edinburgh

Deleuze, G \& F Guattari 1988, A Thousand Plateaus: capitalism \& schizophrenia, Continuum, London

Dewsbury, J 2011 'The Deleuze-Guattarian Assemblage: plastic habits' Area 43, 2: 148-153

Elliott, S 2017 ‘An Interview with Peter Polites’, Antic (n.d.): https://www.anticmagazine.com.au/an-interviewwith-peter-polites/ (accessed 7 June 2018)

Esin, C, M Fathi \& C Squire 2013 'Narrative Analysis: The Constructionist Approach' in U Flick (ed.) The SAGE Handbook of Qualitative Data Analysis, SAGE, London: 203-216

Funk, D \& J James 2006 'Consumer Loyalty: The Meaning of Attachment in the Development of Sport Team Allegiance', Journal of Sport Management 20: 189-217 
Grenville, K 2005 The Secret River, Text, Melbourne

Harman, G 2008 'DeLanda’s ontology: assemblage and realism', Continental Philosophy Review 41: 367-383

Hartcher, P 2007 'Bipolar Nation: How to win the 2007 election', Quarterly Essay 25: 1-60

Heffernan, M 2017 'Darebin Council loses citizenship ceremony rights over Australia Day snub', The Age (22 August): https://www.theage.com.au/national/victoria/darebin-council-loses-citizenship-ceremony-rights-overaustralia-day-snub-20170822-gy1lir.html (accessed 20 September 2018)

Hughes, M 2017 'Review: The Punisher is Brutally Relevant, Emotionally Powerful Win for Marvel-Netflix', Forbes (17 November): https://www.forbes.com/sites/markhughes/2017/11/17/review-the-punisher-is-brutallyrelevant-emotionally-powerful-win-for-marvel-netflix/\#166c8aa1738c (accessed 4 June 2018)

Hyvarinen, M 2012 'Analyzing Narratives and Story-Telling', in P Alasuutari, L Bickman \& J Brannen (eds) The SAGE Handbook of Social Research Methods, SAGE, London: 447-460

Knaus, C \& C Wahlquist 2018 'Abolish Australia Day: Invasion Day marches draw tens of thousands of protesters', The Guardian (26 January): https://www.theguardian.com/australia-news/2018/jan/26/abolishaustralia-day-invasion-day-marches-draw-tens-of-thousands-of-protesters (accessed 20 September 2018)

Kohn, A 2004 'The Wild West Down Under: Comparing American and Australian Expressions of Gun Enthusiasm', Journal on Firearms \& Public Policy 16: 179-205

Lightfoot, S (showrunner) 2017- The Punisher (TV series), Marvel-Netflix, New York

McCann, E 2011 'Veritable Inventions: cities, policies and assemblage', Area 43, 2: 143-147

McFarlane, C \& B Anderson 2011 'Thinking with Assemblage', Area 43, 2: 162-164

McGahan, A 2004 The White Earth, Allen \& Unwin, Crows Nest

McKenna, M 2010 ‘Anzac Day: How did it become Australia’s national day?' in M Lake \& H Reynolds (eds) What's Wrong With Anzac?, University of New South Wales Press, Sydney: 110-134

Marcus, G \& E Saka 2006 'Assemblage’, Theory, Culture \& Society 23, 2-3: 101-109

Mitchell, K 2010, ‘Australia’s “Other” History Wars: Trauma and the Work of Cultural Memory in Kate Grenville's The Secret River, in M Kohlke \& C Gutleben (eds) Neo-Victorian Tropes of Trauma: The Politics of Bearing after-Witness to Nineteenth Century Suffering, Ropodi, Amsterdam: 253-282

Morris, S 2018 'Mass shootings in the US: there have been 1,624 in 1,870 days', The Guardian (16 February): https://www.theguardian.com/us-news/ng-interactive/2017/oct/02/america-mass-shootings-gun-violence (accessed 31 May 2018)

Nail, T 2017 'What is an Assemblage?', SubStance 46, 1: 21-37

Napper, T 2018 ‘The Dark Century 1946-2046: Noir, Cyberpunk and Asian Modernity', PhD thesis, University of Canberra, Canberra

Neijdie, B 1989 Story About Feeling, Magabala Books, Broome

Nolan, M \& R Clarke 2014 'Reading Groups and Reconciliation: Kate Grenville's The Secret River and the Ordinary Reader', Australian Literary Studies 29, 4: 19-35

Pierce, P 1999 The Country of Lost Children: An Australian Anxiety, Cambridge University Press, Cambridge Polites, P 2017 Down the Hume, Hachette Australia, Sydney

Rubbo, M 2008 ‘Tim Winton', Readings (5 May): https://www.readings.com.au/ interview/tim-winton (accessed 7 June 2018)

Russell, B, A Pusey \& P Chatterton 2011 'What can an Assemblage do?', City 15, 5: 577-583

Schultz, J 2017 'Stories we tell ourselves: Terra nullius of the mind', Griffith Review 58: 7-11

Scott, K 1999, Benang: From the Heart, Fremantle Press, Fremantle

Stilz, G 1991 'Topographies of the Self: Coming to Terms with the Australian Landscape in Contemporary Australian Poetry' in G Capone (ed.) European Perspectives: Contemporary Essays on Australian Literature, University of Queensland Press, St Lucia: 55-71 
McHugh 'The narrative of assemblage'

Turner, G 1993 National Fictions, Allen \& Unwin, St Leonards

Turner, G 1994 Making it National: Nationalism and Australian Popular Culture, Allen \& Unwin, St Leonards Wertsch, J 2008 'The Narrative Organization of Collective Memory', Ethos 36, 1: 120-135

White, H 2017 'Without America', Quarterly Essay 68: 1-81

Winton, T 2008 Breath, Hamish Hamilton, Sydney

Wright, A 2006 Carpentaria, Giramondo Publishing, Sydney

Wright, A 2013 The Swan Book, Constable, London 